\title{
The Future as a Series of Transitions: Qualitative Study of Heart Failure Patients and Their Informal Caregivers
}

\author{
Jacqueline Jones, PHD, RN, FAAN ${ }^{7}$, Carolyn T. Nowels, MSPH 2,3, Rebecca Sudore, MD ${ }^{4,5}$, \\ Sangeeta Ahluwalia, $\mathrm{PhD}, \mathrm{MPH}^{\circ}$, and David B. Bekelman, $\mathrm{MD}, \mathrm{MPH}^{2,3}$
}

${ }^{1}$ College of Nursing, University of Colorado, Aurora, CO, USA; ${ }^{2}$ School of Medicine, University of Colorado, Aurora, CO, USA; ${ }^{3}$ Department of Veterans Affairs, Eastern Colorado Health Care System, Denver, CO, USA; ${ }^{4}$ Division of Geriatrics, School of Medicine, University of California, San Francisco, CA, USA; ${ }^{5}$ San Francisco Veterans Affairs Medical Center, San Francisco, CA, USA; ${ }^{6}$ College of Public Health and Human Sciences, Oregon State University, Corvallis, OR, USA.

BACKGROUND: Advance care planning often only focuses on written advance directives rather than on future goals important to patients and families. Heart failure has a particularly uncertain future with variable clinical trajectories. A better understanding of patient and family concerns about and perceptions of the future could improve advance care planning.

OBJECTIVE: We aimed to identify how patients with heart failure and their informal (family) caregivers perceive their future.

DESIGN: This was a cross-sectional study using qualitative methods.

PARTICIPANTS: Thirty-three patients from an academic health care system with New York Heart Association class II-IV heart failure and 20 of their informal caregivers participated in the study. We used a purposive sampling strategy to include patients within a range of ages and health statuses.

APPROACH: Participants were asked in individual, semistructured interviews: "When you think about what lies ahead, what comes to mind?" Qualitative analysis used an inductive approach. Early in the analysis, it became clear that participants' narratives about the future were described in terms of past transitions. This led us to use transition theory to further guide analysis. Transition theory describes how people restructure their reality and resolve uncertainty during change.

KEY RESULTS: Patients and their caregivers talked about past and present transitions when asked about the future: "The present gets in the way of talking about the future." We identified four common pivotal transitions, including the shock of first being diagnosed with heart failure; learning to adjust to life with heart failure; reframing and taking back control of one's life; and understanding and accepting that death is inevitable. Concerns about the future were framed based on the most recent transition.

CONCLUSIONS: Heart failure is a series of transitions according to patients and caregivers. By recognizing and educating patients about transitions, identifying transition-specific concerns, and supporting patients and caregivers through transitions, the process of

Received March 1, 2013

Revised December 18, 2013

Accepted October 10, 2014

Published online November 11, 2014 planning for the future as part of advance care planning may be improved.

KEY WORDS: advance care planning; transitions; palliative care; decision making; patient-centered care.

J Gen Intern Med 30(2):176-82

DOI: $10.1007 / \mathrm{s} 11606-014-3085-5$

(C) Society of General Internal Medicine 2014

\section{INTRODUCTION}

Advance care planning often focuses on making decisions about life-sustaining treatments. However, it is increasingly recognized that patients might have a broader range of wishes for their future beyond preferences for life-sustaining interventions. ${ }^{1-3}$ Heart failure (HF), a leading cause of death, hospitalizations, costs, and disability, has multiple non-linear clinical trajectories, characterized by deterioration and improvement in physical function, frequent hospitalizations, and sudden death. ${ }^{4}$ Because of this unpredictability, patients and their families face numerous uncertainties in the future, such as whether they can work, take trips, or attend family events. ${ }^{5-7}$ Such unpredictability also poses challenges for advance care planning. For example, in our earlier study to identify palliative care needs and support preferences in heart failure (HF) care, some participants and their informal (family) caregivers avoided discussing the future because the future was so uncertain. ${ }^{6}$ Thus, the nature of HF makes it particularly important to understand how patients and their caregivers perceive their changing health and healthcare needs, and how these perceptions relate to concerns and questions about what lies ahead.

Prior research has not directly asked patients with HF or their caregivers how they perceive their future. ${ }^{8-13}$ The future is often narrowly construed as related to prognosis, and several studies focus on preferences for how and when prognosis is communicated. $^{12,14}$ The literature on adjusting to chronic illness generally focuses on the psychological and biomedical consequences of positive or negative adjustment, rather than how perceptions of illness or changing health influence perceptions of the future. ${ }^{15,16}$ A thorough understanding of $\mathrm{HF}$ patients' and their informal caregivers' concerns for the future and how these concerns are influenced could facilitate better 
person-centered communication and promote shared decisionmaking in the primary care setting. ${ }^{3,17}$ This understanding may also help us tailor our approach to advance care planning.

In a prior study, we focused on broad informational and communication needs between patients, doctors, and clinicians. ${ }^{5}$ In order to address the gap in the literature about how patients and their informal caregivers perceive the future in the context of uncertain trajectories of $\mathrm{HF}$, we conducted another qualitative analysis of our interview data to explore in-depth issues related to how HF patients perceive the future.

\section{METHODS}

Data for this analysis were drawn from our previously published study of HF patients and their caregivers, conducted between 2007 and 2008 through a large academic institution's outpatient cardiology and geriatric clinics. ${ }^{5}$ In-depth qualitative interviews were used to explore major concerns and unmet health care needs in those living with heart failure. In addition, questions asked whether, how, and when a palliative care program might be useful to patients and their caregivers. We used a purposive sampling strategy to include patients within a range of ages and health statuses. This was done to obtain perspectives from participants who had the age and illness severity ranges commonly seen in practice. As the study progressed, we actively recruited older adults, as participants who initially entered the study were younger. Eligible patients had a diagnosis of HF and New York Heart Association (NYHA) class II-IV HF. Patients were excluded if they had a diagnosis of dementia. The treating physician, study investigator, or research assistant approached potentially eligible patients after the verbal consent of the treating physician. Patients were asked if they would consider participating in an interview study to help us learn about quality of life issues in HF, and were enrolled if they provided informed consent. Enrolled patients were asked to identify a caregiver for interviews: "Can you think of the one person beside a healthcare provider who helps you the most with your heart condition?" Not all patients identified a caregiver. Study personnel spoke to the caregivers by phone or in person and used the same aforementioned study for patients. All caregivers who were contacted about the study agreed to participate and provided informed consent. Caregivers and patients were interviewed separately in the clinic or at their homes. This study was approved by the Colorado Multiple Institutional Review Board.

Two interviewers who had previous experience with qualitative studies conducted in-depth, semi-structured interviews lasting 60-90 min. After several open-ended questions about major concerns and needs, interview questions covered domains from the National Consensus Project for Quality Palliative Care, including physical, psychological, social, cultural, and spiritual aspects of care. ${ }^{3}$ The interview guides were refined by the study team after the first five interviews, to improve the clarity of interview questions. Interviews were digitally recorded, transcribed verbatim, and entered into
ATLAS.ti ${ }^{18}$ for coding. The analysis focused on specific interview questions related to the future (Text Box 1) or any narratives that the participants shared spontaneously about their future concerns. Patients' medical records were reviewed for NYHA functional class and comorbidities. Participants also completed sociodemographic surveys and self-reported the date they were diagnosed with HF.

\section{Text Box 1. Interview Guide Items}

When you think about your heart condition and what lies ahead for you [for CG: "your spouse, parent, etc.] (say in the next months or 15 years), what comes to mind for you? What have you thought about the future of your [CG: his/her] condition?

- Do you talk with anyone about this? Who do you talk with? [CG only: Do you talk with "your spouse, parent, etc. about this?] Could you tell me a little about those conversations? How helpful or not helpful have the conversations been for you?

- [PT only] What would it look like if you did talk with your family? Who would be there? Where would it take place? Would someone from your health care team be there?

- What things get in the way of talking about this?

$C G$ caregiver, $P T$ patient

\section{Qualitative Analysis}

To explore how patients and their informal caregivers perceived the future, we used a team-based, inductive approach $^{19-21}$ to synthesize and contextualize the interview data related to 'the future.' Team members $(\mathrm{CN}, \mathrm{JJ}, \mathrm{DB})$ individually reviewed transcripts; created and refined the coding schema initially built around the National Consensus Project domains $^{3}$; and wrote analytic memos and notes from team discussions. This team met regularly to conduct an in-depth review of all of these data sources, discussing emerging patterns. We used a continuous process of data immersion and reimmersion and frequent team meetings to discuss emerging themes as well as discrepancies, disconfirming and confirming cases and alternative explanations. ${ }^{20,21}$ An integral part of the analytic process involved ongoing modification of our evolving conceptual framework of themes. ${ }^{20}$

Early in the analysis, it became clear that participants' narratives about the future were strongly shaped by and described in terms of past experiences, particularly past transitions. This prompted us to subsequently use transition theory ${ }^{22-24}$ as a guiding framework to help focus our analysis. According to transition theory, people's responses and adaptation during change such as serious illness can result in new ways of how they view themselves. ${ }^{22,23}$ Transition experiences are complex and have multiple dimensions that are influenced by relationships, environments, interactions and health. Transitions may cause renewed hope or suffering by life disruption, dislocation, disorientation, and limitations. 8,23,24, p324-327 As a consequence, patients who experience a chronic illness such as HF shape their ideas of their future over time through a process of reconstructing how they view themselves. ${ }^{25}$ Therefore, we 
grounded our coding scheme and analytic approach to identify any of these aspects of transition theory.

\section{RESULTS}

A total of 53 individuals participated: 33 patients with HF (from a referral pool of 38 eligible patients; five declined to participate) and 20 of their informal caregivers. Patients were mainly older, male and white, with diversity in education, income and NYHA Class (Table 1). Caregivers were mainly wives or daughters of the patients; half cared for the patients for greater than $8 \mathrm{~h}$ per week (Table 2).

Patients and their caregivers talked about the past and present when asked about the statement: "The present gets in the way of talking about the future." Specifically, participants described concerns related to present or past transitions that influenced how they perceived the future. We identified four common pivotal transitions described by the sample that occurred in the context of the fluctuating trajectory of the illness: 1) the shock of first being diagnosed with HF and its unexpected journey, 2) awareness of and learning to adjust to life with HF, 3) reframing and taking back control of one's life and 4) understanding and accepting death as an inevitable part of living. Sometimes the patients and caregivers had similar concerns about the future. At other times, caregivers described transitions and the future differently, such as when patients were "in denial." Text Box 2 illustrates some of the different descriptions of pivotal transitions using language from both patients and caregivers.

\section{Text Box 2. Examples of transitions According to Patients and Informal (Family) Caregivers}

Pivotal Transition Patient

When first diagnosed

Coming to terms with/learning to adjust

Reframing and taking back control

Death is inevitable, but I (we) live with it again.
... I didn't want to accept it. I still tried to work. I still tried to do things that I normally did. I still tried to go to the gym... and I was making myself worse. It took me about 2 years to realize - to stop!

...when I first got ill it, was like I'm going to fight this. I'm dying and I can't be sick, what are you talking about? This is crazy! ...This isn't happening to me.

Like before when I was on the transplant list I wasn't scared at all. I didn't have my wife and I wasn't scared. I was ready to face it. But since that episode I've gotten married to my wife, this last time it scared me.

...when I got my heart problems, I quit working 7 days a week and $12-15$ h days. I went back to working $5 \frac{1}{2}$ or 6 days, $8 \mathrm{~h}$ a day where if I'd be tired I was in a position I could do that, which was fortunate. But again, I made adjustments every time I've had something. I've had to make some kind of adjustment.

I went back to my doctor and it was like... he is not willing to listen. He is not willing to change any of the medications... I sat there and said...I'm not ready to check out yet. I'm too damned stubborn to let go. But... what I need to do is take back my life... become an advocate for myself, take charge for the things I could take charge of. In my situation, it's every so often I get real sick and then they do something and then it helps me feel better, and so I feel better for 5, 6 or 7 years and then I start going downhill

Probably a feeling of mortality, I guess. Before I wasn't worried about it, if it's my time then it's my time. But now I have a child and a wife, and I want to be here to take care of them.

...work in progress and that never stops. ...I think I'm on the edge of 3 or whatever it is. As I get worse there will be less things I can do. But I don't want to give those up until I have to give them up. And by doing that I think you focus on what you are doing, not what could happen.

I guess through some spiritual enlightenment - is that I really don't need to do anything in life. And to just be calm and be the observer of what's happening in the world instead of being the do-er, or whatever you call it.

I guess you could sit around and think how long am I going to live and I know when I first had my heart attack some of the things went through my mind about limitations and all that, but I got over that. You just have to adjust to what your limitations are. And I don't think about it. I think in terms of if I do these things and do this... so I leave that up to whatever that is, and I just go and I'm at peace with God. I'm at peace.

\section{Caregiver}

When it first happened...we knew he was about dead when he went into the hospital... [then] he started to feel better. You know, it's like... 'this isn't too bad. Why can't I go back to doing this and why do I have to take all these drugs?' It's that denial.

Well, when he comes down [stairs] in the morning, he usually doesn't go up until the evening. He tries to have everything, you know, until he is ready to go to bed or do laundry or whatever he stays downstairs. So he is learning to stay down.

$\mathrm{He}$ is a little more dependent on me. I used to depend on him more... [now] he has me do the talking [to other people] sometimes. It was time we moved here [to a townhome], but you do miss your home and the life you had then.

...he's just kind of figured out what he can do and what he can't do when he takes his meds... I know that a lot of the time they try to adjust his medication and he won't do it... when they try to adjust things, he knows if he does he's going to end up feeling crappy. So he... kind of works with them to do what he knows is the best for himself...he knows his own body more than they do. But when he realized that this heart thing - that they were able to control it one way or another, he started then being able to face his new reality. That he is going to live.

That is the bottom line. We would be very lucky if we grow old together. I don't look forward to the day. I know I must, but I don't look forward to the day. We just get today. I don't know about on a daily basis, but it [death] is just something that is in the back of your mind, you know.

I have a little bit of a fear of that [the future]. I'm thankful every day that we still have each other. But we plan. We know that someday one of us...we know it's going to happen. It's just as normal as being born. 
Table 1. Patient Characteristics $(n=33)$

\begin{tabular}{|c|c|}
\hline Age (years, median [range]) & $64[33-91]$ \\
\hline Women, N (\%) & $10(30.3)$ \\
\hline \multicolumn{2}{|l|}{ Race, $\mathrm{N}(\%)(n=32)$} \\
\hline Native American & $3(10.3)$ \\
\hline Black & $7(24.1)$ \\
\hline White & $17(58.6)$ \\
\hline Hispanic/Latino & $3(10.3)$ \\
\hline Other & $2(6.9)$ \\
\hline \multicolumn{2}{|l|}{ Current relationship status $(n=27)$} \\
\hline Married & $11(37.9)$ \\
\hline Divorced & $7(24.1)$ \\
\hline Widowed & $4(13.8)$ \\
\hline Separated & $1(3.5)$ \\
\hline Never married & $4(13.8)$ \\
\hline \multicolumn{2}{|l|}{ Highest grade completed in school $(n=29)$} \\
\hline Less than high school grad & $1(3.5)$ \\
\hline High school grad/GED & $14(48.3)$ \\
\hline Some college & $7(24.1)$ \\
\hline College grad & $4(13.8)$ \\
\hline Any post-grad & $3(10.3)$ \\
\hline \multicolumn{2}{|l|}{ Total household income $(n=26)$} \\
\hline$<\$ 20,000$ & $11(42.3)$ \\
\hline$\$ 20,001-30,000$ & $3(11.5)$ \\
\hline$\$ 30,001-40,000$ & $3(11.5)$ \\
\hline$\$ 40,001-50,000$ & $4(15.4)$ \\
\hline$\$ 50,001-60,000$ & $2(7.7)$ \\
\hline$\$ 60,001-70,000$ & $1(3.9)$ \\
\hline$>\$ 70,000$ & $2(7.7)$ \\
\hline \multicolumn{2}{|l|}{ NYHA class, n $(\%)$} \\
\hline II & $11(39.3)$ \\
\hline III & $13(46.4)$ \\
\hline IV & $4(14.3)$ \\
\hline \multicolumn{2}{|l|}{ Comorbid conditions, $\mathrm{n}(\%)$} \\
\hline Hypertension & $22(66.7)$ \\
\hline Diabetes & $14(42.4)$ \\
\hline Atrial febrillation & $20(60.6)$ \\
\hline Stroke & $4(12.1)$ \\
\hline COPD & $11(33.3)$ \\
\hline Time since diagnosis, (years, median [range], $n=25$ & $5[>1-27]$ \\
\hline
\end{tabular}

*A patient could select more than one racialethnic category

1. The future when first diagnosed- 'a journey you didn't expect to have'

For many, the diagnosis of HF was confusing and difficult to absorb. Some people talked about being "in shock" at first when they were told about the diagnosis of HF. Others expressed denial and subsequent unwillingness to accept its life-limiting nature. Patients did not understand what HF was, what had happened to their heart, what might have caused their HF, or what HF would be like to live with. Patients described being unaware of choices and alternatives in the future. For others, the diagnosis served as a "wake-up call" necessitating lifestyle changes. Caregivers described HF as " $a$ journey you didn't expect to have." One described her husband as "in denial" after he was hospitalized and "nearly dead." This caregiver questioned why her husband couldn't resume his previous activity level after the hospitalization when he was feeling better.

The initial diagnosis raised many questions about the trajectory of the disease. Both patients and caregivers asked how HF might affect their life, work, or relationships with their family. Both worried about how to take care of their home or do things they enjoyed. In addition, both patients and caregivers shared that "because it's so new, I don't even know what
Table 2. Caregiver Characteristics $(N=19) *$

\begin{tabular}{ll}
\hline \hline Age, (years, median [range]) & $59[30-89]]$ \\
Women, N (\%) & $18(94.7)$ \\
Relationship to patient, N (\%) & \\
Wife & $8(42.1)$ \\
Partner/significant other & $1(5.3)$ \\
Daughter & $6(31.6)$ \\
Son & $1(5.3)$ \\
Other relative & $1(5.3)$ \\
Other (ex-wife) & $2(10.5)$ \\
Highest grade completed in school & \\
Less than high school grad & $-4(21.5)$ \\
High school grad/GED & \\
Some college & $6(31.5)$ \\
College grad & $5(26.3)$ \\
Any post-grad & $4(21.5)$ \\
Current relationship status, N (\%) $\dagger$ & \\
Married & $11(61.1)$ \\
Divorced & $3(16.6)$ \\
Widowed & - \\
Separated & $1(5.5)$ \\
Never married & $1(5.5)$ \\
Member of unmarried couple & $2(11.1)$ \\
Employment status, N (\%) & \\
Working full-time & $9(47.3)$ \\
Working part-time & $4(21.0)$ \\
Retired & $4(21.0)$ \\
Unemployed & $1(5.2)$ \\
Other & $1(5.2)$ \\
Hrs per week caring for patient, N (\%) ${ }^{\dagger}$ & \\
<1 & $2(11.1)$ \\
1-2 & $1(5.6)$ \\
3-5 & $3(16.7)$ \\
6-8 8 & $3(16.7)$ \\
*20 completed interviews, 19 completed surveys, ${ }^{\dagger} \boldsymbol{N}$ responding=18
\end{tabular}

questions [about the future] to ask my doctor." Others grappled with uncertainty and asked "How long will I have?"

2. The future as 'coming to terms with and learning to adjust'

After having time to let the news of their HF diagnosis "sink in," some patients and caregivers felt like they had reached a "new phase." No longer in shock or "denial," patients and caregivers acknowledged that HF is a condition they would live with for the rest of their lives, and the disruptions to a 'normal' life (including giving up employment) would not go away. Patients began to be aware of ways to adapt to HF, such as scheduling appointments so that they could rest in the afternoon. Patients also adjusted their expectations to a "new normal" of what they could do to better fit with their energy level. Caregivers took on tasks previously performed by their loved ones, such as outside chores or talking on the telephone, resulting in role adjustments. Others downsized their home. In the midst of these changing roles, patients expressed concern about the burden their illness placed on those around them.

Future trips or plans were approached with uncertainty by both patients and caregivers. Sometimes caregivers reflected back on ' who' their loved one "used to be" and on the lifestyle they themselves used to have, including prior employment. Caregivers described emotional tolls from ambiguous new roles and strained or isolated relationships with their loved ones. Both patients and caregivers struggled with the 
uncertainty in the future, asking themselves a recurring question: "I wish I knew how long I have got." Many were frustrated with interactions with the healthcare system and providers around this issue. Furthermore, both patients and caregivers described limited consultation time to talk, plan ahead, and re-adjust to new information as their health changed.

3. Owning their future, reframing and taking back control: 'you've got to own it'

The uncertain trajectory of HF brought many decisions about hospitalizations, going through rehabilitation, whether to make changes to medications, or whether to implant a cardiac device, such as a defibrillator. Faced with these decisions over time, some patients became more proactive and wanted to participate to a greater extent in their care. Some patients experienced a shift between "drifting along" with their HF to beginning to "steer" their day-to-day life more. In this phase, patients felt like "I have control here"; patients talked about "having to own [HF]." Patients had more knowledge about their condition and how to live with it. Some were able to say "you know, this is how I think I want to handle my HF." Patients "claimed their role" in living with HF rather than feeling they had "lost control" to HF, to the doctors, the medications or the medical measures of how sick they were (e.g., ejection fractions). Patients often experienced a sense of inner re-orientation or changed self-identity. One patient talked about the "freedom" he felt after deciding not to undergo a transplant procedure. Another found meaning and a renewed sense of self-worth through offering support to others with HF. As patients felt more in control of their illness, caregivers' observed their loved ones set limits with healthcare providers on how many new medications or changes to existing medication regimens they were prepared to try.

\section{Death is part of the future: 'death is inevitable, but I (we) live with it'}

Both patients and caregivers also discussed the "ultimate future," or end of life. Both realized that death may be a part of any serious health condition, including HF, and conveyed a sense of inevitability. Both experienced personal growth associated with renewed reflection on life. Patients no longer questioned whether they would die, but rather accepted that they will die at some point; patients talked about "when my heart stops." Patients accepted that reaching the end of their life is part of living with HF, because HF is not a curable condition. Both patients and caregivers became reconciled with the fact that the trajectory or life course of HF is "uncertain." Both patients and caregivers talked about "taking it day by day" but didn't really worry about death as their future in an urgent way. Caregivers used less 'physical' or 'body' words to describe death's proximity. Rather, caregivers described the anticipated loss of time with their loved one, the "knowing" that time together is limited, and life is about each day. Some caregivers were angry or frustrated about the concept of their loved ones' mortality, especially if limited prognosis or end of life issues had not been discussed between them. Other patients and caregivers spoke of their faith in God or of their spirituality guiding their comfort with death's inevitability.

\section{DISCUSSION}

Patients with HF and their caregivers described the future in terms of how they experienced pivotal transitions in the present and past. Four pivotal transitions framed the illness trajectory: the shock of first being diagnosed with HF; learning to adjust to life with HF; reframing and taking back control of one's life; and understanding and accepting death is inevitable. Recent theoretical work has hypothesized that transitions are important in $\mathrm{HF}^{22}$ However, this study actually illustrated common transitions as experienced by patients with $\mathrm{HF}$ and their caregivers, and the subsequent adjustment in how patients view themselves and anticipate their future.

While adjustment to loss was common across all transitions, hope or personal growth also emerged in response to critical events or triggers. ${ }^{22}$ Mishel's theory of uncertainty in chronic illness ${ }^{26}$ identified that transitions can bring personal or spiritual growth and result in a positive experience. Although an event may seem negative to a provider, the patient and or caregiver may experience new perspectives on life, death or existential reality. ${ }^{3,8}$ The fourth transition, understanding and accepting death is inevitable, is evidence that such growth is possible. Studies have identified that, as positive adjustment to health status occurs, tolerance for uncertainty can increase, reducing fear and emphasizing living life to the fullest now. ${ }^{27-29}$

Because transitions facilitated re-framing and adjustment to the reality of illness, supporting patients and caregivers through this process might help to strengthen relationships, redefine roles, and reconstruct self-identity. ${ }^{22}$ In addition, helping patients and caregivers understand transitions as a potential for anticipating new beginnings, such as a new phase of living with their illness, in addition to grieving and coming to terms with endings, may facilitate "transition agility," the ability to make transitions throughout the illness trajectory with minimal distress. ${ }^{22,30}$

For clinicians, recognizing, acknowledging, and educating patients and caregivers about transitions could be important steps in helping patients and caregivers plan for the future in a process of "anticipatory guidance." This guidance could supplement traditional advance care planning. For example, primary care providers could explain the nature and course of HF both in the traditional disease progression framework and as a series of transitions for both patients and caregivers. Primary care providers can highlight that these transitions can bring personal growth and new perspectives to patients and caregivers, yet they may often require support during adjustment. Asking patients and caregivers about prior transitions could help them identify their strengths and resources in order to navigate current transitions and prepare for potentially 
challenging transitions in the future. Primary care providers can ask for input from both patients and caregivers during this process. For example, patients may not recognize when they are in denial or shock, but caregivers may.

Furthermore, understanding how patients and caregivers are adjusting to transitions can inform primary care providers about the level of advance care planning patients and caregivers can tolerate. Some patients may struggle or get stuck during a transition, unable to consider the future. When the provider is able to provide empathy and support for the patient's transition experiences, patients may feel more at peace and in control of their illness such that they can set limits to therapeutic interventions without feeling like they are "giving up. ${ }^{, 31}$ It is tempting to think that transitions are an ideal time to revisit goals of care and advance care planning because of the changes involved. However, the findings indicate that at times during transitions, patients and caregivers are overwhelmed with coming to terms with the transition and are unable to discuss the future.

Several limitations should be considered. The sample, although purposefully generated to maximize variation across age and health status, was identified from one health system. While the sample reflected diversity in education, income, and NYHA Class, there were more white male patients in our sample than of HF patients in general in the US, which may have influenced the findings. Participants provided retrospective accounts of previous and current concerns regarding the future. A prospective, longitudinal study design would provide additional and confirmatory data related to the changing nature and context of the future for HF patients and their caregivers. We used primary data from our prior study that were framed appropriately to the study question, but as a secondary analysis, there was no opportunity to iteratively probe emergent themes or to test the transition patterns in this sample.

In conclusion, by offering a preliminary understanding of common transitions, these results provide insights into how patients with symptomatic HF and their caregivers perceive and experience the future. Identifying transitions, as well as preparing patients and their informal caregivers for future transitions as part of advance care planning, may be useful additions to care in HF. Determining if communication about transitions in HF reduces distress and improves outcomes for quality palliative care, shared decision-making and quality of life are an important next steps for providers and researchers.

\footnotetext{
Acknowledgements: Funders: This research was funded by the University of Colorado Hartford/Jahnigen Center for Excellence in Geriatric Medicine and the Mordecai Palliative Care Grants Fund. Dr. Bekelman is funded by a Department of Veterans Affairs Career Development Award (HSR\&D CDA 08-022). The funding organizations had no role in any part of the study. The views expressed in this paper are those of the authors and do not necessarily reflect the views of the Department of Veterans Affairs.
}

Prior Presentations: None.
Conflict of Interest: The authors declare that they do not have any conflicts of interest.

Corresponding Author: Jacqueline Jones, PHD, RN, FAAN; College of Nursing, University of Colorado, Campus Box C-288-19, 13120 E. 19th Ave, Aurora, CO 80045, USA (e-mail: jacqueline.jones@ucdenver.edu).

\section{REFERENCES}

1. Sudore RL, Fried TR. Redefining the "planning" in advance care planning: preparing for end-of-life decision making. Ann Intern Med. 2010;153(4):256-61.

2. McMahan R, Knight SJ, Fried TR. Sudore RL Advance care planning beyond Advance Directives: perspectives from patients and surrogates. J Pain Symptom Manage. 2013;46(3):355-65.

3. National Consensus Project for Quality Palliative Care. Clinical Practice Guidelines for Quality Palliative Care, Third Edition. Available at: http:// www.nationalconsensusproject.org. Accessed October 21, 2014

4. Lunney JR, Lynn J, Foley DJ, Lipson S, Guralnik JM. Patterns of functional decline at the end of life. JAMA. 2003;289(18):2387-92.

5. Ahluwalia SC, Levin JR, Lorenz KA, Gordon HS. "There's no cure for this condition" : How physicians discuss advance care planning in heart failure. Patient Edu Couns. 2013;91:200-2005.

6. Bekelman DB, Nowels CT, Retrum JH, et al. Giving voice to patients' and family caregivers' needs in chronic heart failure: implications for palliative care programs. J Palliat Med. 2011;14:1317-24.

7. Jones J, McDermott C, Nowels C, Matlock D, Bekelman D. The experience of fatigue as a distressing symptom of heart failure. Heart \& Lung. 2012;41(5):484-91.

8. Charmaz K. Stories of suffering: Subjective tales and research narratives. Qual Health Res. 1999;9(3):362-82.

9. Allen LA, Yager JE, Funk MJ, et al.Discordance between patientpredicted and model-predicted life expectancy among ambulatory patients with heart failure. JAMA. 2008;299(21):2533-42.

10. Boyd KJ, Murray SA, Kendall M, Worth A, Benton TF, Clausen H. Living with advanced heart failure: a prospective, community based study of patients and their carers. Eur J Heart Fail. 2004;6:585-59.

11. Selman L, Harding $\mathbf{R}$, Benyon $\mathbf{T}$, et al. Improving end-of-life care for patients with chronic heart failure: "Let's hope it'll get better, when I know in my heart of hearts it won't.”. Heart. 2007;93:963-7.

12. Arthur PH, Caldwell HM, Demers C. Preferences for patients with heart failure for prognosis communication. Can J Cardiol. 2007;23(10):791-6.

13. Steinhauser KE, Christakis NA, Clipp EC, McNeilly M, McIntyre L, Tulsky JA. Factors considered important at the end of life by patients, family, physicians, and other care providers. JAMA. 2000;284(19):2476-82.

14. Dougherty CM, Pyper GP, Au DH, Levy WC, Sullivan MD. Drifting in a shrinking future: living with advanced heart failure. J Cardiovasc Nurs. 2007;22(6):480-7.

15. De Ridder D, Geenen R, Kuijer R, van Middendorp H. Psychological adjustment to chronic disease. Lancet. 2008;372:246-55.

16. Sharpe L, Curran L. Understanding the process of adjustment to illness. Soc Sci Med. 2006;62:1153-66.

17. Institute of Medicine. 2001 Crossing the quality chasm. Available at: http: / /iom.edu/Reports / 2001/Crossing-the-quality-chasm-a-newhealth-system-for-the-21st-century.aspx. Accessed October 21, 2014.

18. ATLAS.ti 6.2. 2008; Berlin: Scientific software development.

19. Maxwell JA. Qualitative research design: An interactive approach. 3rd ed. Thousand Oaks, CA: Sage Publications; 2013.

20. Richards L, Morse JM. Read me first for a user's guide to Qualitative Methods. 3rd ed. Thousand Oaks, CA: Sage Publications; 2013.

21. Saldana J. The coding manual for qualitative researchers. 2nd ed. London, UK: Sage Publications; 2013.

22. Davidson PM, Dracup K, Phillips J, Padilia G, Daly J. Maintaining hope in transition: A theoretical framework to guide interventions for people with heart failure. J Cardiovasc Nurs. 2007;22(1):58-64.

23. Meleis AI, Sawyer LM, Im EO, Hilfinger M, DeAnne K, Shumacher K. Experiencing transitions: An emerging middle range theory. ANS Adv Nurs Sci. 2000;23(1): 12-28.

24. Kralik D, Visentin K, van Loon A. Transition: A literature review. J Adv Nurs. 2006;55(3):320-9.

25. Charmaz K. Good Days, Bad days: The Self in Chronic Illness and Time. New Brunswick: NJ Rutgers University Press; 1991. 
26. Mishel MH. Reconceptualization of the uncertainty in illness theory. $J$ Nurs Scholarsh. 1990;22(4):256-62.

27. Mishel MH, Germino BB, Gil KM, et al. Benefits from an uncertainty management intervention for African-American and Caucasian older longterm breast cancer survivors. Psychooncology. 2005;14(11):962-78.

28. Kurita K, Garon EB, Stanton AL. Meyerowitz BE Uncertainty and psychological adjustment in patients with lung cancer. Psychooncology. 2013;22:1396-1401.
29. Mauro AMP. Long-term follow-up study of uncertainty and psychosocial adjustment among implantable Cardioverter defibrillator recipients. Int $\mathrm{J}$ Nurs Stud. 2010;47:1080-88.

30. Waterworth S, Jorgensen D. It's not just about heart failure-voices of older people in transition to dependence and death. Health Soc Care Community. 2010;18(2):199-207.

31. Tulsky JA. Beyond advanced directives: importance of communication skills at the end of life. JAMA. 2005;294(3):359-65. 